\title{
A PROPOSED NEW VEGETATION INDEX, THE TOTAL RATIO VEGETATION INDEX (TRVI), FOR ARID AND SEMI-ARID REGIONS
}

\author{
Hadi Fadaei ${ }^{a^{*}}$, Rikie Suzuki $^{\text {b }}$, Tetsuro Sakai ${ }^{\mathrm{c}}$ and Kiyoshi Torii ${ }^{\mathrm{d}}$ \\ ${ }^{a}$ Postdoctoral Researcher at Research Institute for Global Change (RIGC), Japan Agency for Marine-Earth Science and \\ Technology (JAMSTEC)-fadaei@jamstec.go.jp \\ ${ }^{\mathrm{b}}$ Research Institute for Global Change (RIGC), Japan Agency for Marine-Earth Science and Technology (JAMSTEC)- \\ rikie@jamstec.go.jp \\ ${ }^{c}$ Department of Social Informatics, Graduate School of Informatics, Kyoto University Kyoto, Japan \\ ${ }^{\mathrm{d}}$ Graduate Schools of Agriculture, Kyoto University, Kyoto, Japan
}

KEY WORDS: Arid and semi-arid, ALOS, Total Ratio Vegetation Index (TRVI), Pistachio and Juniper

\begin{abstract}
:
Vegetation indices that provide important key to predict amount vegetation in forest such as percentage vegetation cover, aboveground biomass, and leaf-area index. Arid and semi-arid areas are not exempt of this rule. Arid and semi-arid areas of northeast Iran cover about 3.4 million ha and are populated by two main tree species, the broadleaf Pistacia vera (pistachio) and the conifer Juniperus excelsa ssp. polycarpos (Persian juniper). Natural stands of pistachio in Iran are not only environmentally important but also genetically essential as seed sources for pistachio production in orchards. We investigated the relationships between tree density and vegetation indices in the arid and semi-arid regions in the northeast of Iran by analysing Advanced Land Observing Satellite (ALOS) data PRISM is a panchromatic radiometer with a $2.5 \mathrm{~m}$ spatial resolution at nadir, and has one band with a wavelength of $0.52-0.77 \mu \mathrm{m}$ (JAXA EORC). AVNIR-2 is a visible and near infrared radiometer for observing land and coastal zones with a $10 \mathrm{~m}$ spatial resolution at nadir, and has four multispectral bands: blue $(0.42-0.50 \mu \mathrm{m})$, green $(0.52-0.60 \mu \mathrm{m})$, red $(0.61-0.69 \mu \mathrm{m})$, and near infrared $(0.76-0.89 \mu \mathrm{m})$ (JAXA EORC). In this study, we estimated various vegetation indices using maximum filtering algorithm $(5 \times 5)$ and examined. This study carried out of juniper forests and natural pistachio stand using Advanced Land Observing Satellite (ALOS) and field inventories. Have been compared linear regression model of vegetation indices and proposed new vegetation index for arid and semi-arid regions. Also, we estimated the densities of juniper forests and natural pistachio stands using remote sensing to help in the sustainable management and production of pistachio in Iran. We present a new vegetation index for arid and semi-arid regions with sparse forest cover, the Total Ratio Vegetation Index (TRVI), and we investigate the relationship of the new index to tree density by analysing data from the Advanced Land Observing Satellite (ALOS) using $5 \times 5$ maximum filtering algorithms. The results for pistachio forest showed the coefficient regression of NDVI, SAVI, MSAVI, OSAVI, and TRVI were $(\mathrm{R} 2=0.68,0.67,0.68,0.68$, and 0.71$)$ respectively. The results for juniper forest showed the coefficient regression of NDVI, SAVI, MSAVI, OSAVI, and TRVI were $(\mathrm{R} 2=0.51,0.52,0.51,0.52$, and 0.56$)$ respectively. I hope this research can provide decision of managers to helping sustainable management for arid and semi-arid regions in Iran.
\end{abstract}

\section{INTRODUCTION}

Arid and semi-arid areas of northeast Iran cover about 3.4 million ha and contain two main tree species, the broadleaf Pistacia vera. L (pistachio) and the conifer Juniperus excelsa ssp. polycarpos (Persian juniper), which are found at different elevations above sea level (a.s.l.) (Figure 1). Persian juniper forms open woodlands, with a maximum tree density of approximately 150 trees per hectare (pers. obs.; Andrew et al. 1996). This species is found from Turkey to Afghanistan and east and south to Iran (Fisher and Andrew 1995) and at elevations ranging from 1500 to $2900 \mathrm{~m}$ a.s.1., and is also found in Pakistan, where it is fairly common, forming open forests in Baluchistan and inner dry valleys of the Himalayas from 1200 to $4000 \mathrm{~m}$ (Andrew et al. 1996). However, the climate at these altitudes may be marginal for the survival of Persian juniper, and even small increases in climatic stress could imperil the present status of these woodlands (Fisher and Andrew 1995). Pistachio is thought to have been cultivated for 3000-4000 years in Iran. Currently, Iran is the world's largest producer of pistachio, followed by the United States, where most pistachio production is in California. In 2004, Iran and the United States were responsible for $44 \%$ and $13 \%$ of global pistachio production, respectively (Razavi 2006). Pistachios are one of the most important non-oil exports from Iran (Fadaei et al. 2007). Most pistachio production in Iran occurs in orchards, but there are a few areas, such as in northeast Iran, where wild pistachio (Pistacia vera L.) grows in natural stands, mostly at elevations of 500-1200 m (a.s.1.). Natural stands of pistachio are important, not only environmentally but also genetically as seed storage for pistachio production in orchards. In addition, natural pistachio stands, which are managed by the Natural Resource Organization of Iran, provide rural residents with opportunities to obtain extra income by participating in harvesting.

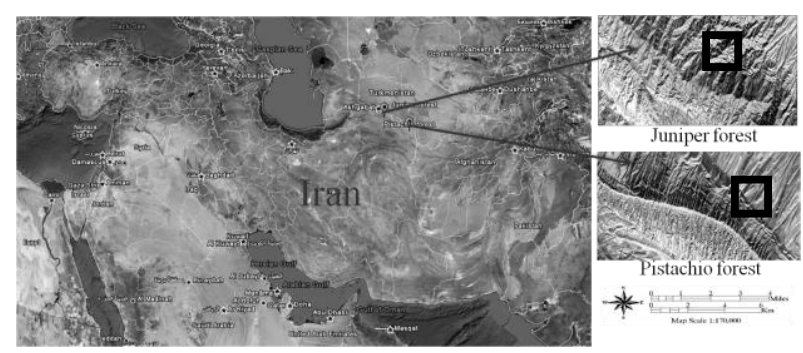

Figure 1. Locations of the study areas in northeast Iran

\footnotetext{
* Corresponding author. Tel.: +81-45-778-5605; fax: +81-45-778-5706. E-mail address: fadaei@ jamstec.go.jp
} 
The purpose of the present study is to determine the density of natural pistachio and Persian juniper stands using remotesensing data, especially Advanced Land Observing Satellite (ALOS) data, and generally to help in the sustainable management and production of these forests in northeast Iran. We applied the local-maxima approach to determine the tree density of natural pistachio and Persian juniper stands, and conventional vegetation indices in related to arid and semi-arid. We propose a new vegetation index, the total ratio vegetation index (TRVI), for arid and semi-arid regions (Figure 2).

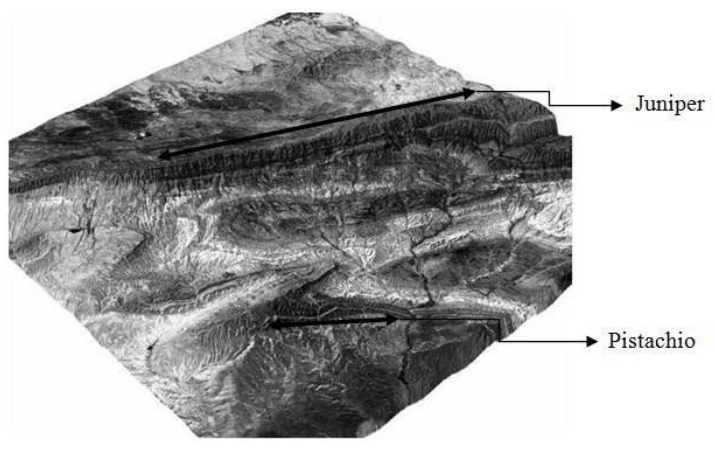

Figure 2. Locations of the study areas in northeast Iran

\section{MATERIAL AND METHODS}

\subsection{Study area}

\section{Pistachio area}

The study site was located in an arid area of northeast Iran where pistachio trees grow wild; annual precipitation is 200 $300 \mathrm{~mm}$ (Ramazani 2002). The site was $15.21 \mathrm{~km} 2(3.9 \times 3.9$ $\mathrm{km})$ with latitudinal and longitudinal ranges of $36^{\circ} 17^{\prime} 2.60^{\prime \prime}-$ $36^{\circ} 7^{\prime} 2.09^{\prime \prime} \mathrm{N}$ and $60^{\circ} 30^{\prime} 21.91^{\prime \prime}-60^{\circ} 30^{\prime} 18.22^{\prime \prime} \mathrm{E}$, respectively. Natural pistachio forests occur mostly at elevations of 900 $1500 \mathrm{~m}$, and the elevation of the study site was $500-1200 \mathrm{~m}$. The slope of the site generally ranged from 15 to 35 degrees. Among 169 grid squares $(300 \mathrm{~m} \times 300 \mathrm{~m})$ in a $13 \times 13$ arrangement, 15 sampling plots were randomly chosen for analysis (Figure 3). Wild pistachio trees at the study site were typically 3-4 m high, with crown diameters of 3-5 m (Figure 2 ). These forests were sparse and trees were widely spaced. The distance between two pistachio trees was often more than $3 \mathrm{~m}$, and these gaps contained shrubs adapted to dry terrain, such as Amygdalus spinosissima, Atraphaxis spinosa, Cerasus pseudprostrata, Ephedra intermedia, Tamarix androssowii, and Zygophyllum eurypterum. Soil salinity at the study site, measured by the Natural Resources Organization of Iran, was 0.6-20 mmhos/cm (U.S. Salinity Laboratory Staff, 1969), indicating that the site is a non-saline to strongly saline area (U.S. Salinity Laboratory Staff, 1969).

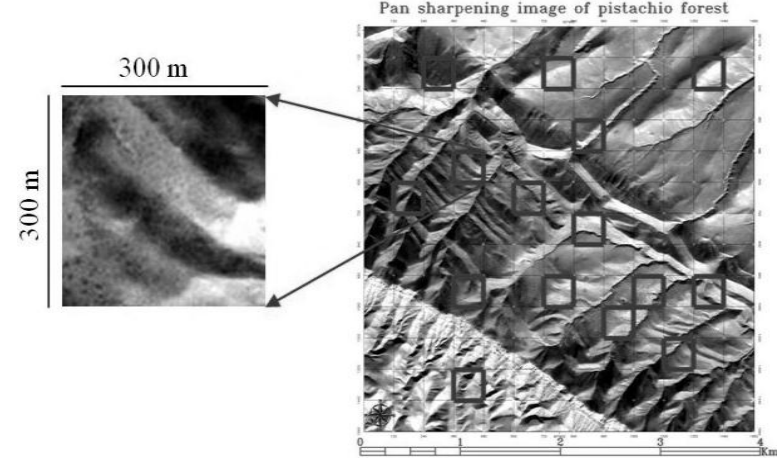

Figure 3. Arrangement of the 9-ha pistachio sampling plots. The 15 highlighted plots are those randomly chosen for analysis Juniper area

The study site was located in an arid area of northeast Iran where Persian Juniper trees are found naturally. Annual precipitation is $156 \mathrm{~mm}$ (Fadaei et al. 2009), and the study site covers $15.21 \mathrm{~km} 2(3.9 \times 3.9 \mathrm{~km})$ between $37^{\circ} 20^{\prime} 31.19^{\prime \prime}-$ $37^{\circ} 18^{\prime} 22.30^{\prime \prime} \mathrm{N}$ and $58^{\circ} 49^{\prime} 59.13^{\prime \prime}-58^{\circ} 52^{\prime} 34.40^{\prime \prime} \mathrm{E}$. The elevation is $700-900 \mathrm{~m}$, and the slope ranges from 21 to 27 degrees. Among 169 grid squares $(300 \mathrm{~m} \times 300 \mathrm{~m})$ in a $13 \times 13$ arrangement, 12 sampling plots were randomly chosen for analysis. The trees at the study site were typically 3-4 m high, with crown diameters of 3-5 m (Figure 4). These forests are typically sparse and the trees widely spaced.

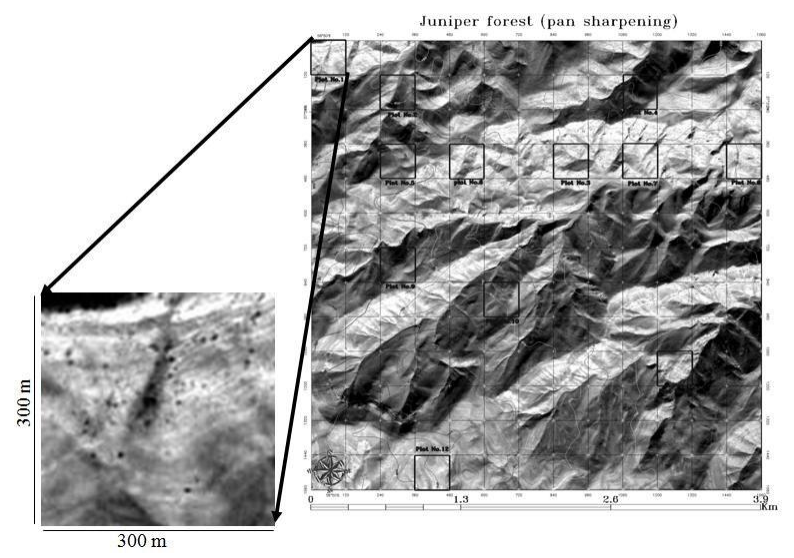

Figure 4. Arrangement of the 9-ha juniper sampling plots. The 12 highlighted plots are those randomly chosen for analysis

\section{Image data}

We used satellite imagery that was acquired in July 2008 by ALOS, which was launched on 24 January 2006. ALOS data have good resolution in the panchromatic and multispectral bands, which are appropriate for the study area, and are not too expensive. Among three remote-sensing instruments on-board ALOS, the Panchromatic Remote-sensing Instrument for Stereo Mapping (PRISM) and the Advanced Visible and Near Infrared Radiometer type 2 (AVNIR-2) were used for digital elevation mapping and precise land coverage observations, respectively. PRISM is a panchromatic radiometer with $2.5-\mathrm{m}$ spatial resolution at nadir, and has one band with a wavelength of $0.52-0.77 \mu \mathrm{m}$ (JAXA EORC). AVNIR-2 is a visible and near infrared radiometer for observing land and coastal zones with a 10-m spatial resolution at nadir, and has four multispectral bands: blue $(0.42-0.50 \mu \mathrm{m})$, green $(0.52-0.60 \mu \mathrm{m})$, red $(0.61-$ $0.69 \mu \mathrm{m})$, and near infrared $(0.76-0.89 \mu \mathrm{m})($ JAXA EORC). 


\section{Vegetation indices}

In remote sensing applications, the most commonly used vegetation index for detecting vegetation. Here you can see the properties of each vegetation index that introduce by others scientist (Table 1).

\section{New vegetation index}

In arid and semi-arid regions, soil background has more reflectance in the near infrared (NIR) and red (RED) wavelengths of vegetation. Soil components that affect spectral reflectance include color, roughness, and water content. Roughness also has the effect of decreasing reflectance because of an increase in multiple scattering and shading. RED-NIR scattergrams, termed the "soil line", are used as a reference point in most vegetation studies. The problem is that real soil surfaces are not homogeneous and contain a composite of several types. Analysis has shown that for a given soil characteristic, variability in one wavelength is often functionally related to reflectance in another wavelength. Vegetation cover is usually sparse compared to soil background and soil and plant spectral signatures tend to mix non-linearly. Thus, arid plants tend to lack the strong red edge found in plants of humid regions due to ecological adaptations to the harsh desert environment. We decided to introduce a new vegetation index based on total wavelength (visible and NIR). The TRVI is the ratio of NIR and the sum of visible and NIR wavelengths, and is calculated using the following equation:

$$
T R V I=4\left(\frac{N I R-R E D}{(N I R+R E D+G+B)}\right)
$$

where RED and NIR stand for spectral reflectance measurements acquired in the red and near-infrared regions, respectively. For this equation, the normalized difference is divided by the total of visible and near infrared wavelengths. In this equation, "4" is the measured reflectance. In fact, this equation shows the ratio of the normalized difference of reflectance and measured reflectance of all bands, i.e., the four bands in the multispectral image. In this study, TRVI was used to estimate the stand density of Persian juniper and wild pistachio trees.

\begin{tabular}{|c|c|c|c|}
\hline VIs & Formula & Presented & Summary \\
\hline $\begin{array}{l}\text { Normalize } \\
\mathrm{d} \\
\text { Difference } \\
\text { Vegetation } \\
\text { Index } \\
\text { (NDVI) }\end{array}$ & $N D V I=\frac{N I R-R E D}{N I R+R E D}$ & $\begin{array}{l}\begin{array}{l}\text { Rouse et al. } \\
(1974)\end{array}\end{array}$ & $\begin{array}{l}\text { RED and NIR stand for } \\
\text { spectral reflectance } \\
\text { measurements acquired } \\
\text { in the red and near- } \\
\text { infrared regions, } \\
\text { respectively }\end{array}$ \\
\hline $\begin{array}{l}\text { Soil- } \\
\text { Adjusted } \\
\text { Vegetation } \\
\text { Index } \\
\text { (SAVI) }\end{array}$ & $S A V I=\frac{(N I R-R E D)(1+L)}{N I R+R E D+L}$ & Heute (1988) & $\begin{array}{l}\mathrm{L} \text { indicates the soil- } \\
\text { brightness dependent } \\
\text { correction factor that } \\
\text { compensates for differences } \\
\text { in soil background } \\
\text { condition, L=1 low } \\
\text { vegetation densities, } \mathrm{L}=0.5 \\
\text { intermediate vegetation } \\
\text { densities and } \mathrm{L}=0.25 \text { higher } \\
\text { densities }\end{array}$ \\
\hline $\begin{array}{l}\text { Modified } \\
\text { Soil } \\
\text { Adjusted } \\
\text { Vegetation } \\
\text { Index } \\
\text { (MSAVI) } \\
\end{array}$ & MSAVI $=\frac{1}{2}\left[2 \times N I R+1-\sqrt{(2 \times N I R+1)^{2}-8 \times(\text { NIR }-R E D)}\right]$ & Qi et al. (1994) & $\begin{array}{l}\text { The dynamic range of the } \\
\text { inductive MSAVI was } \\
\text { slightly lower than that of } \\
\text { the empirical } \mathrm{L} \text { function } \\
\text { due to differences in } \mathrm{L} \\
\text { boundary conditions }\end{array}$ \\
\hline $\begin{array}{l}\text { Optimized } \\
\text { Soil- } \\
\text { Adjusted } \\
\text { Vegetation } \\
\text { Index } \\
\text { (OSAVI) } \\
\end{array}$ & OSAVI $=\frac{(N I R-R E D)}{N I R+R E D+0.16}$ & $\begin{array}{l}\text { Rondeaux et al. } \\
(1996)\end{array}$ & $\begin{array}{l}\text { The value of } 0.16 \text { in this } \\
\text { formula was found to } \\
\text { produce a satisfactory } \\
\text { reduction in soil noise, both } \\
\text { for low and high vegetation } \\
\text { cover }\end{array}$ \\
\hline
\end{tabular}

Table 1. The properties of conventional vegetation indices

\section{Tree counting}

Using a GPS device, we located the centres and corners of each 9-ha plot based on satellite imagery input to the GPS. Then, starting in a plot corner, we measured densities of juniper and pistachio trees on all the plots. This was done in cooperation with the regional natural resources organization.

\section{Methods of analysis}

We calculated linear regression coefficients between tree density and vegetation index values. Tree density for each plot was obtained from the field surveys. Vegetation indices were calculated using ALOS satellite data for each 9-ha plot (14400 data points). Subsequently, we used $5 \times 5$ maximum filtering algorithms for vegetation index data from each plot to determine the optimum maximum spectral value for pistachio and juniper trees. We also calculated frequency results for $5 \times 5$ maximum filtering of vegetation indices from each plot. Finally, simple linear regressions between tree density and vegetation index values were calculated based on the best threshold vegetation index values. All of these analyses were performed using ENVI (Environment for Visualizing Images) software, service pack 1, and Microsoft Excel 2007.

\section{RESULTS AND DISCUSSION}

3.1 Relationship between vegetation indices and tree density for the $5 \times 5$ maximum filtering algorithm for pistachio

A simple linear regression between the conventional vegetation indices, new TRVI vegetation index and tree density based on the $5 \times 5$ maximum filtering algorithm was calculated. For all of the vegetation indices, the relationship between tree density and vegetation value was positive. NDVI and OSAVI had similar $\mathrm{R}^{2}$ values and plot distributions and higher than other vegetation indices.

According to Colwell (1974), background reflectance can have an important effect on canopy reflectance, especially with low values of percentage vegetation cover (Figure 5).

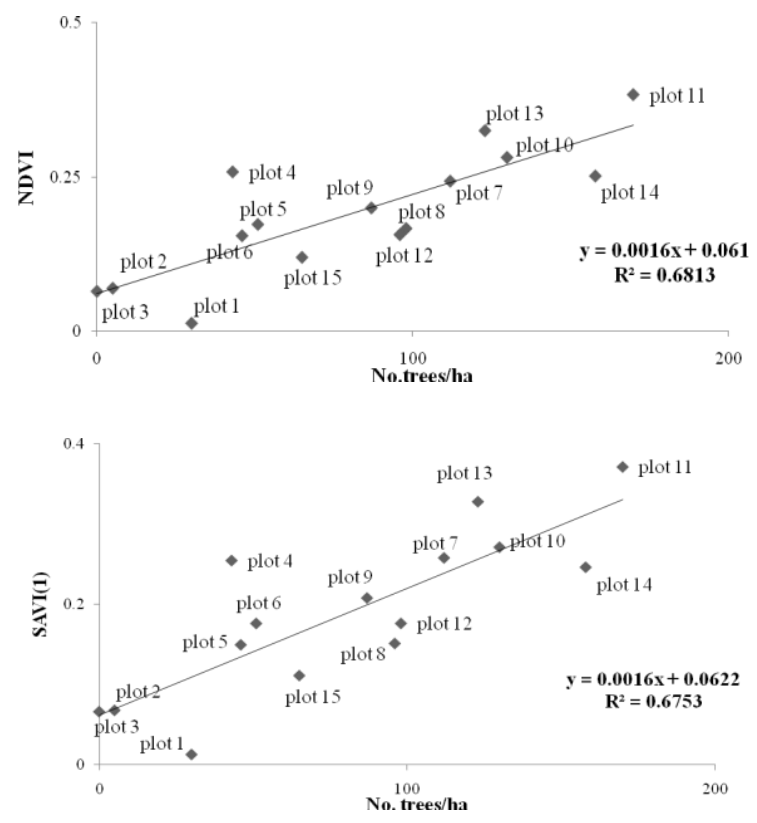



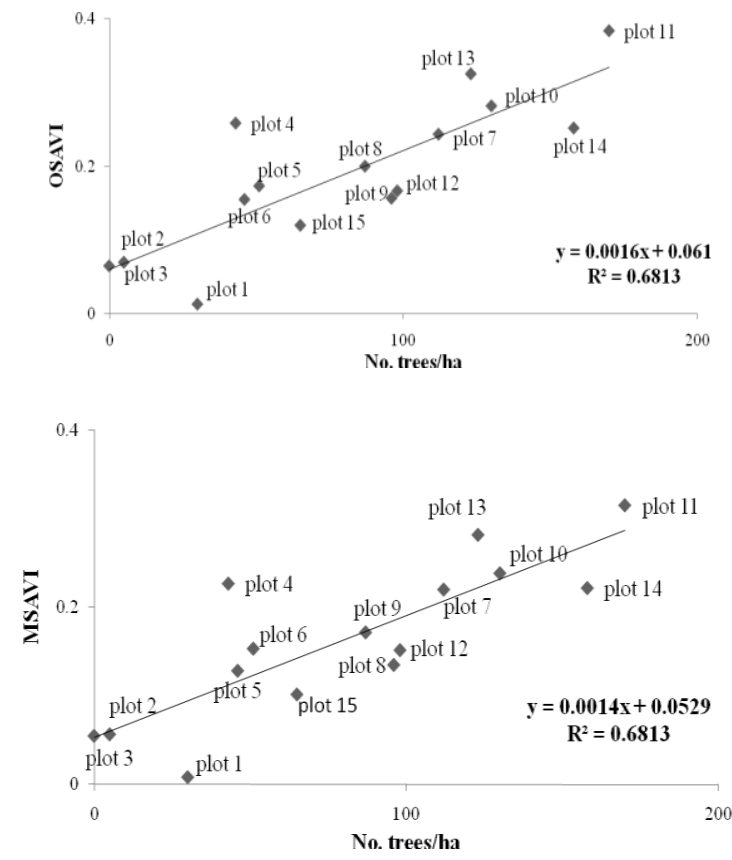

Figure 5. Relationships between tree density and vegetation indices (VIs)

3.2 Relationship between vegetation indices and tree density for the $5 \times 5$ maximum filtering algorithm for juniper

A simple linear regression between the conventional vegetation indices, new TRVI vegetation index and tree density based on the $5 \times 5$ maximum filtering algorithm was calculated. In the field survey, we observed that plots with few juniper trees had more ground vegetation, as shown in the significant positive relationship. Vegetation that is dead or stressed reflects more red lights and less NIR light. Likewise, non-vegetated surfaces have much more even reflectance across the light spectrum. In arid and semi-arid regions, the NDVI is low, particularly in forests where vegetation cover is sparse compared to the soil background. The NDVI is sensitive to the optical properties of the soil background (Baret and Guyot, 1991) (Figure 6).
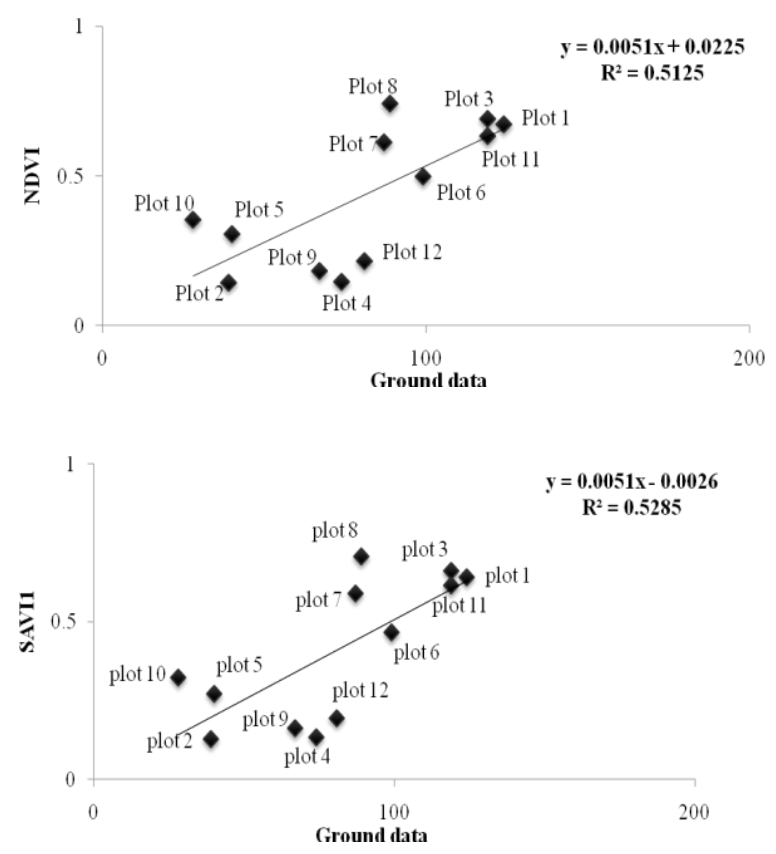
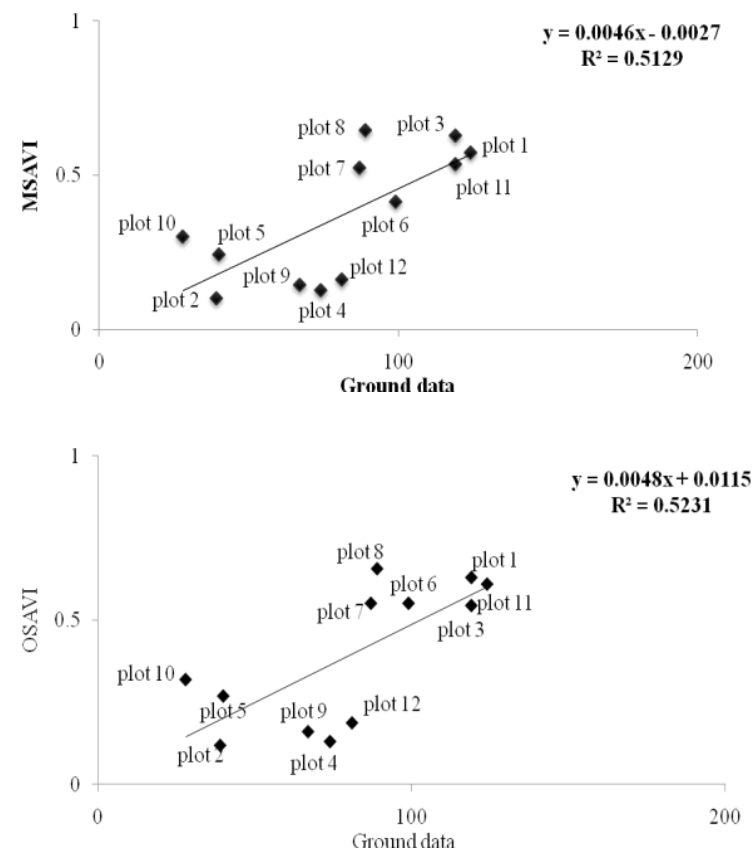

Figure 6. Relationships between tree density and vegetation indices (VIs)

3.3 Relationship between new vegetation index and tree density for the $5 \times 5$ maximum filtering algorithm for both area

In the arid and semi-arid regions, soil type is very important; thus, we attempted to reduce the confounding effect of the soilvegetation interaction by using optimum window sizes to obtain spectral values for TRVI. Generally, in arid and semi-arid regions, the green vegetation index tends to decrease with lowreflecting soil backgrounds, and the influence of soil background has been found to seriously hamper the assessment and characterization of vegetation canopy cover (Huete et al. 1985; Huete and Jackson 1987). The relationship between TRVI and tree density was positive. TRVI values were generally higher than the conventional vegetation indices(Figures 7 and $8)$.

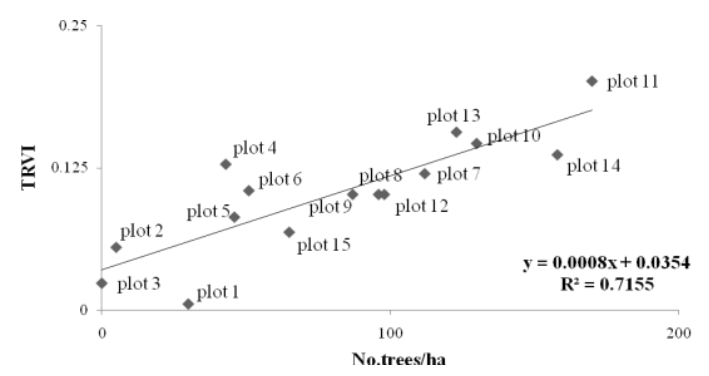

Figure 7. The relationship between pistachio tree density and TRVI vegetation index 


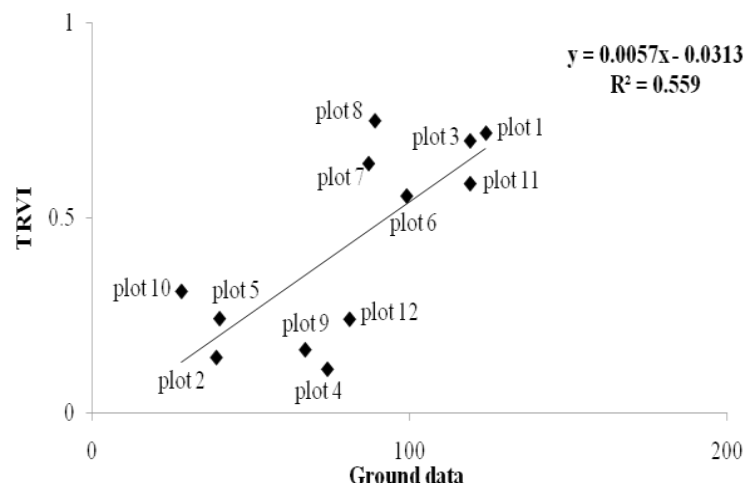

Figure 8 . The relationship between juniper tree density and TRVI vegetation index

\section{CONCLUSION}

In this study, we identified and delineated pistachio and juniper trees in arid and semi-arid regions of Iran to facilitate forest inventories in this area. We introduced a new vegetation index (TRVI) for arid and semi-arid regions based on the spectrum of multispectral wavelengths. We applied this index for estimation of tree density in pistachio and Persian juniper forests. One limitation of this research is the method used to distinguish trees from other forms of vegetation. The relationships developed between number of pistachio or juniper trees and TRVI were all significant for green biomass. The new vegetation index, TRVI, was shown to be appropriate for arid and semi-arid areas. TRVI produces more consistent results and is as easy to use as NDVI. By simply inputting data for the other visible wavelengths, improved results for sparse forests in arid and semi-arid regions are produced. Additional work in this area using data collected from March to October is needed to fully evaluate TRVI for arid and semi-arid regions in different months. Arid and semi-arid vegetation has special adaptations to hydrological and thermal stresses, and hence special methods are required to extract the vegetation cover from satellite imagery, which may be key to extracting vegetation cover using hyper spectral wavelengths.

\section{Acknowledgement}

This study was carried out under the support of the Environment Research and Technology Development Fund (S9) of the Ministry of the Environment of Japan.

\section{References}

Andrew, S. G., and Fisher, M., 1996. The distribution and status of the montane juniper woodlands of Oman. Biogeography, 23, pp. 791-803.

Baret, F., and Guyot, G., 1991, Potentials and limits of vegetation indices for LAI and APAR assessment. Remote Sensing of Environment, 35 (2-3), pp. 161- 173.

Colwell, J.E., 1974. Vegetation canopy reflectance, Remote Sens. Environ. 3, pp. 175-183.

Fadaei, H., Etemad, V., and Mohamadzadeh, H., 2007. The role of forests in rural communities employment. The First Student National Conference on Youth, Employment and Natural Resources, Iran. Tehran (in Persian), page 44.

Fadaei, H., T. Sakai, Yoshimura, T. and Moriya, K., 2009. Estimation of tree density in the juniper forest of north-east Iran by ALOS. Proceedings of the International Conference on Multipurpose Forest Management, Niigata, Japan, page 47.
Fisher, M., and Andrew, S.G., 1995. The status and ecology of a Juniperus excelsa subsp. polycarpos woodland in the northern mountains of Oman. Vegetatio, 119, pp. 33-51. http://www.eorc.jaxa.jp/ALOS/en/about/avnir2.htm http://www.eorc.jaxa.jp/ALOS/en/about/prism.htm

Huete, A.R., and Jackson, R.D., 1987. Suitability of spectral indices for evaluating vegetation characteristics on arid rangelands. Remote Sensing of Environment, 25, pp. 89-105. Huete, A.R., Jackson, R.D. and Post, D.F., 1985. Spectral response of a plant canopy with different soil backgrounds. Remote Sensing of Environment, 17, pp. 37-53.

Ramazani, M., 2002. Study of the ecology and phenology of pistachio ( $P$. vera) in the Abkhiz location of Ghareh-Ghom, Khorasan. Diploma of Natural Resources, Tarbiat Moddares University. 148 pp. (in Persian).

Razavi, S., 2006. Pistachio production, Iran vs. the World. Acta Hortic, 726, pp. 689-694.

Rondeaux, G., Steven, M. and Baret, F., 1996. Optimization of soil-adjusted vegetation indices. Remote Sensing of Environment, 55, pp. 95-107.

Rouse, J.W., R.H. Haas and Deering, D.W., 1974. Monitoring vegetation systems in the Great Plains with ERTS. In 3rd ERTS Symposium, Goddard Space Flight Center, Greenbelt, MD. NASA SP-351. Vol. 1. pp. 309-317.

U.S. Salinity Laboratory Staff, 1969, Diagnosis and improvement of saline and alkali soils. U.S. Superintendent of Documents, Washington, DC. Agriculture Handbook 60, 160 pp. 